\title{
Preliminary evidence of a biomass-burning event from a 60 year-old firn core from Antarctica by ion chromatographic determination of carboxylic acids
}

\author{
R. Udisti, S. Begagli, R. Traversi, S. Vermigli, G. Piccardi \\ Department of Public Health and Environmental Analytical Chemistry, University of Florence, Via G. Capponi 9, I-50121 Florence, Italy
}

\begin{abstract}
An ion chromatographic method for the determination of fluoride and some organic anions (lactate, acetate, glycolate, propionate, formate, methane sulphonate and pyruvate) at sub- $\mu \mathrm{g} \mathrm{I}^{-1}$ concentration levels is applied to a $22 \mathrm{~m}$ (63 years) firn core drilled at Hercules Névé, northern Victoria Land, Antarctica. The first effective distribution data of acetate, propionate and formate for this region are reported here. Mean values of 9.9, 7.7 and $2.4 \mu \mathrm{gl}^{-1}$ were calculated for acetate, formate and propionate, respectively, in the absence of particular events (background values).

The temporal (1928-82) concentration/depth profiles of these components showed a probable long-term biomass-burning event in the 1930s that can be related back to processes in the Southern Hemisphere. Such burning events may be demonstrated from the simultaneous concentration increase of carboxylic acid, potassium, ammonium and fluoride and from a very high dust content. Similar increasing trends in the same time period are not shown by other snow components usually considered as source indicators (methane sulphonic acid: biogenic marker; nssSO ${ }_{4}{ }^{2}$ : biogenic and volcanic indicator; $\mathrm{Na}^{+}$and $\mathrm{Cl}^{-}$: sea-spray contribution; $\mathrm{Ca}^{2+}$ : crustal input), so it was possible to exclude such alternative explanations.
\end{abstract}

\section{INTRODUGTION}

In areas of undisturbed snow accumulation it is possible to determine, by using the correct chemical and isotopic tracers, individual snow layers accumulated layer by layer over time. By assuming a close correlation between the atmospheric aerosol composition and the snow composition (Lambert and others, 1983; Pourchet and others, 1983) and considering, where possible, the effects of eventual post-depositional processes, a detailed history of the annual and seasonal variation of the atmospheric composition from the snow chemical analysis can be reconstructed.

In northern Victoria Land, East Antarctica, the relative closeness of plateau-like or high-altitude névé areas to the coastline, and to the Italian Terra Nova Bay base, makes access to undisturbed snow-accumulation sites easier. Chemical and physical analyses of firn and ice cores sampled in such areas permit the observation of environmental variations over several decades with detailed analyses of the seasonal behaviour of the main and secondary sources of atmospheric aerosol.

The study of carboxylic acid presence in Antarctic snow can give useful information about sources and transport processes of the oxidation products of substances related to biological cycles (Berresheim, 1987; Keene and Galloway, 1988; Legrand and Saigne, 1988; Andreae and others, 1990; Watts and others, 1990). Although many sources were postulated for carboxylic acids in polar atmosphere (such as direct input from biologic activity or secondary emission by oxidation of marine and continental biogenic hydrocarbons), further studies are indispensable for understanding their atmospheric cycles and their role in the weak acidity of snow precipitation (Legrand and de Angelis, 1995, 1996).

Formate and acetate are directly emitted by vegetation and biomass-burning or from anthropogenic activity (Talbot and others, 1988, 1990). The biomass-burning, usually underestimated, can represent a significant input of hydrocarbons in remote areas. In particular, the methane produced yearly by biomass-burning is about $7 \%$ of global methane emissions (Dignon, 1995). Formic acid production is related to the oxidation processes of hydrocarbons emitted by forest areas (mainly isoprene) and to the natural cycle of formaldehyde (Jacob, 1986; Jacob and Wofsy, 1988, 1990). Measurements of acetic and formic acid in polar snow are sporadic. The first detailed investigation of carboxylic acid presence in Greenland can be found in two recent papers of Legrand and de Angelis $(1995,1996)$ concerning GRIP project samples.

The presence of propionate in atmospheric precipitation was shown by measurements in rainwater (Tsidouridou and Puxbaum, 1987; Murray, 1989), but propionate measurements on snow samples from Antarctica and Greenland are missing. In superficial snow and ice samples collected at Terra Nova Bay, East antarctica, the concentration of propionate was always below the detection limit (Udisti and others, 1991).

In this paper an ion chromatographic (IC) method for the determination of some organic anions and fluoride at sub- $\mu \mathrm{g} \mathrm{l^{-1 }}$ concentration levels is applied to a $22 \mathrm{~m}$ firn core from Hercules Névé, Antarctica. The first data on distribution and temporal profiles (about 60 years) of some shortchain carboxylic acids (formic, acetic and propionic acid) 
in northern Victoria Land are reported here. Preliminary concentration/depth results show a probable biomass-burning event, occurring in the 1930s, evidenced by high levels of carboxylic acids, fluorides, potassium and, with less evidence, ammonium.

\section{METHODOLOGY}

\section{Sampling site}

During the 1993-94 Italian Antarctic Campaign, a 22 m firn core was drilled at Hercules Névé station, northern Victoria Land. Figure 1 shows the geographic position of the sampling site. Northern Victoria Land is a region with a complex orography influenced by strong katabatic winds (personal communication from B. Stenni, 1997), so an accurate preliminary study was necessary to isolate relatively undisturbed sampling areas. Satellite photos showed that Hercules Névé is not influenced by snowdrifts and sastrugi, so that this area seems to be unaffected by wind redistribution effects. A previous shallow firn core $(8 \mathrm{~m}$; Udisti, 1996) confirmed an undisturbed annual snow deposition.

Hercules Névé is a plateau of approximately $1100 \mathrm{~km}^{2}$, about $3000 \mathrm{~m}$ a.s.l. and about $75 \mathrm{~km}$ from the sea (Lady Newnes Bay). It comprises the largest ice cap of northern Victoria Land with the adjacent Evans Névé. The site is located on the ice divide between the glaciers that flow into the Ross Sea and into the Pacific Ocean.

Mean annual temperature values of about $-33^{\circ} \mathrm{C}$ were estimated for the sampling station from the temperature data $\left(-34.5^{\circ}\right.$ and $-33.1^{\circ} \mathrm{C}$ at 7.5 and $10 \mathrm{~m}$ depth, respectively) measured during the firn coring (personal communication from B. Stenni, 1997).

\section{Sampling and analytical procedures}

During the coring, sampling and analysis procedures, all precautions were taken to minimise contamination, and the personnel wore clean-room clothing. The firn core was drilled using a SIPRE rotating ice-corer (electrical $1000 \mathrm{~W}$ engine) with a stainless-steel corer tube $(10 \mathrm{~cm}$ diameter, $120 \mathrm{~cm}$ long) and fibreglass corer rods $(120 \mathrm{~cm} \mathrm{long})$. This corer was accurately cleaned before use and produced core segments $80-90 \mathrm{~cm}$ long. These were cleaned externally on site, labelled and placed in double polyethylene sealed bags. The firn-core sections were kept frozen and brought to the clean-cold room of the Laboratoire de Glaciologie in Grenoble, France (Maggi and Petit, 1998). The firn core was cleaned by mechanically removing a thin external layer, and subsamples were obtained by cutting the firn cores about every $5 \mathrm{~cm}$. These were stored at $-20^{\circ} \mathrm{C}$ in precleaned polyethylene containers placed in double polyethylene bags. Due to electrical failure of a cold store, the first $4 \mathrm{~m}$ were not analyzed.

In the analytical laboratory of the University of Florence the samples, still in their containers, were melted just before analysis under a class-100 laminar-flow hood and filtered on a pre-cleaned $0.45 \mu \mathrm{m}$ Teflon membrane immediately after melting. Particular care was taken to open the containers as little as possible, in order to minimise any uptake of ammonia and carboxylic acid from the laboratory atmosphere (Udisti and others, 1991, 1994).

org/10.3189/S026030550001778X Published online by Cambridge University Press

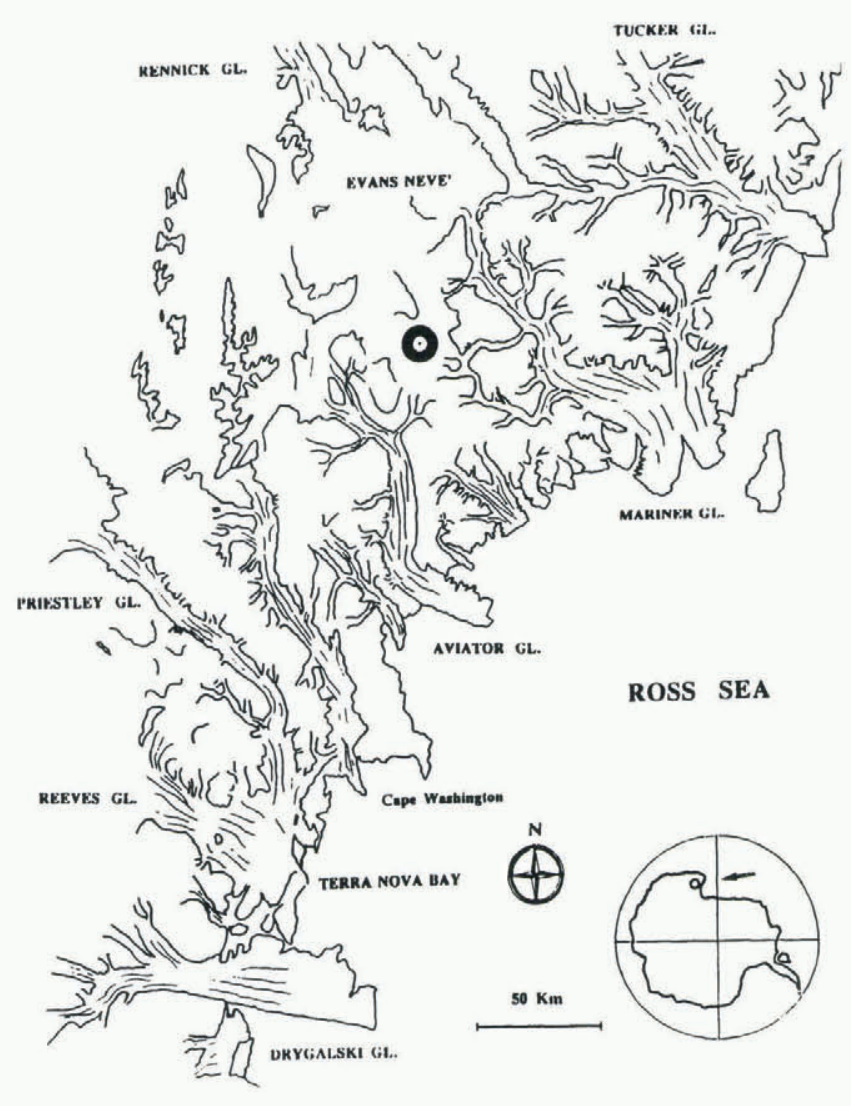

Fig. 1. Geographic position of the sampling station: station 36, Hercules Névé ( $73^{\circ} 06^{\prime} S, 165^{\circ} 28^{\prime}$ E; 2960 m a.s.l.), about $90 \mathrm{~km}$ from the coastline.

\section{Experimental}

\section{Apparatus}

The chemical analysis was performed using a Dionex 4000i IC equipped with a gradient pump and a conductivity detector (CDM-1). The conductivity suppression was performed by an electrochemical anion membrane suppressor (Dionex ASRS-1). The anion separation was obtained by a Dionex AGll guard column and a Dionex ASll separator column. Tetraborate 0.9 and $30 \mathrm{mM}$ was used as eluent according to a step-eluent separation procedure. The eluent was degassed and pressurised with helium by an eluent degas module (Dionex EDM-2). The chromatographic data were collected and elaborated by Dionex PeakNet integration software. A $1 \mathrm{ml}$ loop was used for all sample analysis.

\section{Reagents}

Stock standard solutions $\left(\mathrm{g} \mathrm{l}^{-1}\right)$ were purchased from Merck when available, or obtained from "reagent grade" Merck or Fluka reagents dissolved in ultra-pure water (resistivity $>18 \mathrm{M} \Omega$ ). Standard solutions with lower concentration were prepared daily in pre-cleaned polyethylene bottles.

\section{RESULTS AND DISGUSSION}

\section{Analytical method}

The organic anions (lactate, acetate, propionate, glycolate, formate, methane sulphonate and pyruvate, plus fluoride) are present in snow from Antarctica at very low concentrations, ranging from sub- $\mu \mathrm{gl}^{-1}$ to $\mu \mathrm{gl}^{-1}$ levels. Moreover, these anions are weakly retained into the IC separator columns used for the inorganic anion determination (eluent: 
$\mu \mathrm{S}$
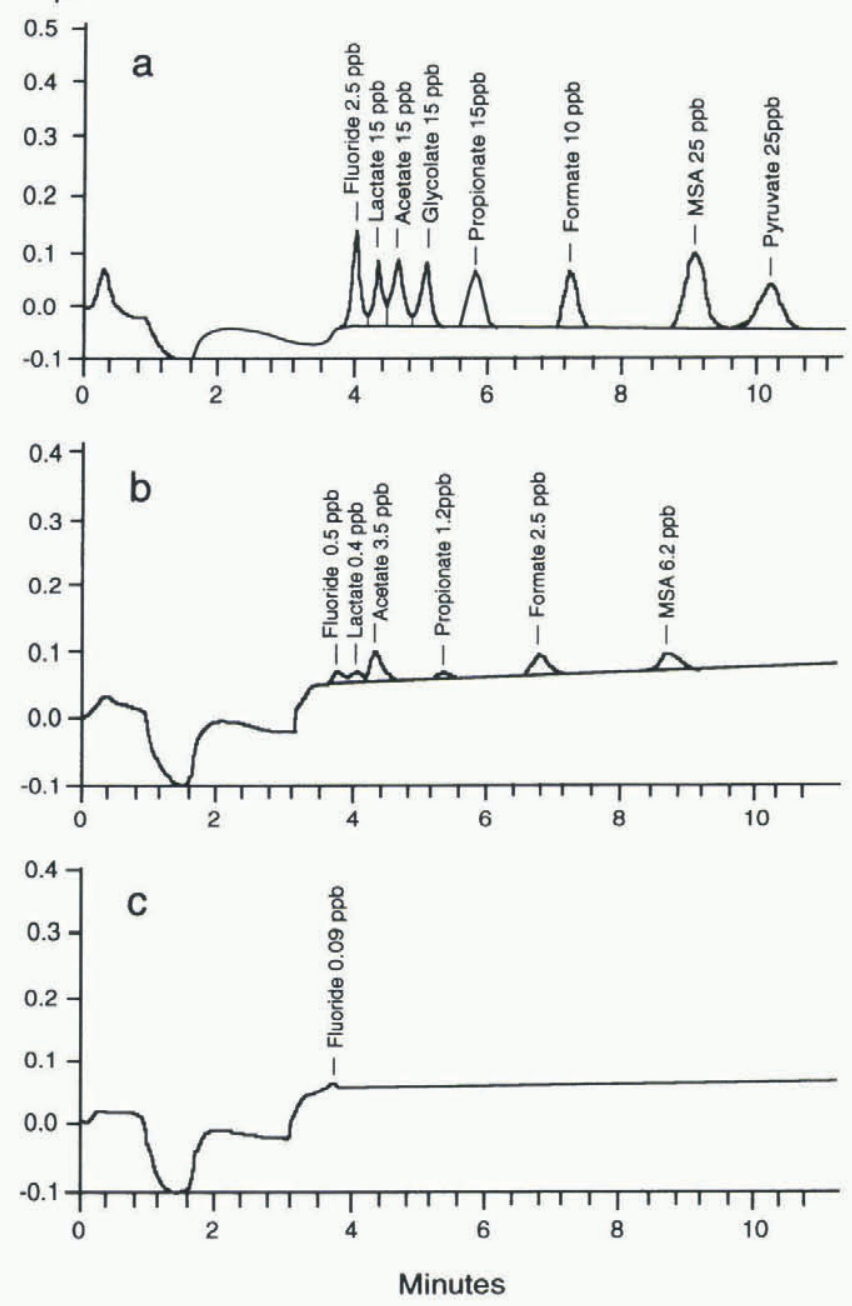

Fig. 2. (a) Chromatographic separation of fluoride and some organic anions (standard solution). The components determined and their concentrations are reported at the top of each peak. Operative conditions and step-eluent programme: Separation and guard columns: Dionex AS11+AG11; loop: $1 \mathrm{ml}$; eluent flow: $2 \mathrm{ml} \mathrm{min}^{-1}$.

Eluents: El.1 $=\mathrm{H}_{2} \mathrm{O}$ Milli-Q; El.2 $=30 \mathrm{mM} \mathrm{Na}_{2} \mathrm{~B}_{4} \mathrm{O}_{7}$, El.3 $=3 \mathrm{mM} \mathrm{Na}_{2} \mathrm{~B}_{4} \mathrm{O}_{7}$.

$\begin{array}{ccccl}\text { Time } & \% \text { El.1 } & \% \text { El.2 } & \% \text { El.3 } & \text { Comment } \\ 0.0 & 70 & 0 & 30 & \text { Start of analysis } \\ 7.5 & 0 & 100 & 0 & \text { Start of cleaning } \\ 12.5 & 70 & 0 & 30 & \text { Stabilisation }\end{array}$

(b, c) Chromatogram of a real sample from Hercules. Névé station ( $b$ ), compared with operational blank (c); same conditions as above. The components determined and their concentrations are reported at the top of each peak $\left(p p b=\mu g \Gamma^{-1}\right)$. carbonate/hydrogencarbonate buffer) so that their separation is difficult. An IC method for a complete separation of the considered components and able to determine sub- $\mu \mathrm{g} \mathrm{l}^{-1}$ concentration levels is required.

Various methods for the simultaneous determination of organic and inorganic anions are reported in the literature (Rocklin and others, 1987; Cheam, 1989, 1992; Legrand and others, 1993). They are usually based on a gradient elution with $\mathrm{NaOH}$ solutions. Under the reported conditions, however, the separation between some components with similar retention times (in particular, acetate/glycolate/propionate and methane sulphonic acid (MSA)/pyruvate) is insufficient for their simultaneous determination. Moreover, the baseline drift, due to the $\mathrm{NaOH}$ concentration gradient, prevents the determination of low concentrations. The detection limits reported for the baseline subtraction technique (Cheam, 1989) $\left(10-80 \mu \mathrm{gl}^{-1}\right.$; loop $\left.=50 \mu \mathrm{l}\right)$ are too high to analyze Antarctic samples with $\mu \mathrm{gl}^{-1}$ or sub- $\mu \mathrm{gl}{ }^{-1}$ concentrations. After a comparison of three IC methods (ion exclusion and anionic exchange in isocratic and gradient mode), Cheam (1992) concluded that the isocratic method produces more reproducible results and lower detection limits.

Udisti and others (1994) proposed two alternative methods based on isocratic or gradient separation using a Dionex AS5A-5 $\mu \mathrm{m}$ separator column and tetraborate as eluent. The gradient methods gave better separation (in particular between acetate and propionate) but lower reproducibility by baseline drift. The isocratic method, on the other hand, did not fully separate some components. In this paper, the isocratic method was improved using a Dionex ASll separator column and $0.9 \mathrm{mM}$ tetraborate as eluent. In effect, after the separation of the organic acids, a more concentrated $\mathrm{Na}_{2} \mathrm{~B}_{4} \mathrm{O}_{7}$ solution $(30 \mathrm{mM})$ is pumped into the system to elute the inorganic anions trapped in the column. Therefore, the above "isocratic" method should be called a "step-eluent" method. During the cleaning step, the inorganic anions are quickly eluted without effective separation.

$\mathrm{Na}_{2} \mathrm{~B}_{4} \mathrm{O}_{7}$ was preferred to $\mathrm{NaOH}$ because of its lower capacity to absorb atmospheric $\mathrm{CO}_{2}$. The carbonate so formed increases the eluent strength to the detriment of the measurement reproducibility. The use of degassed (helium) $\mathrm{Na}_{2} \mathrm{~B}_{4} \mathrm{O}_{7}$ solutions kept retention times stable for more than a week (Udisti and others, 1991).

The chromatogram of a standard solution containing $2.5-25 \mu \mathrm{g} \mathrm{l}^{-1}$ of all the analyzed components is shown in Figure 2, which also shows the experimental conditions.

Table 1 shows the analytical performance of the method (linearity range, sensitivity, reproducibility and detection limits) for acetate, propionate and formate. The reproduci-

Table 1. Linearity range, reproducibility and detection limit for acetate, propionate and formate. Same conditions as Figure 2

\begin{tabular}{|c|c|c|c|c|c|c|c|c|c|}
\hline \multirow[t]{2}{*}{ Component } & \multirow{2}{*}{$\begin{array}{c}\text { Lin. range } \\
\text { ppb }\end{array}$} & \multirow{2}{*}{$\begin{array}{l}\text { Sensitivity } \\
\mathrm{nS} / \mathrm{ppb}\end{array}$} & \multicolumn{3}{|c|}{ Reproducibility } & \multicolumn{4}{|c|}{ Detection limit } \\
\hline & & & $\begin{array}{l}\text { Conc. } \\
\text { ppb }\end{array}$ & $\begin{array}{c}\text { Mean } \\
\mathrm{mS}\end{array}$ & $\begin{array}{c}\text { Std. dev. } \\
\%\end{array}$ & $\begin{array}{l}\text { Conc. } \\
\text { ppb }\end{array}$ & $\begin{array}{c}\text { Mean } \\
\mathrm{mS}\end{array}$ & $\begin{array}{c}\text { Std. dev. } \\
\%\end{array}$ & $\begin{array}{c}\text { Det.lim. } \\
\text { ppt }\end{array}$ \\
\hline Acetate & $0-150$ & 10.6 & 50.0 & 648.8 & 1.6 & 0.5 & 12.7 & 8.7 & 87 \\
\hline Propionate & $0-150$ & 5.8 & 50.0 & 380.0 & 1.4 & 1.0 & 6.7 & 7.5 & 149 \\
\hline Formate & $0-380$ & 13.9 & 50.0 & 749.5 & 1.5 & 0.5 & 9.7 & 9.0 & 89 \\
\hline
\end{tabular}

Notes: The linearity range was obtained with at least 12 calibration points. Mean and standard deviation values were calculated using ten consecutive measurements of the same standard. The detection limit was calculated as twice the standard deviation obtained from ten replicate measurements of standard solutions with concentration of $0.5 \mathrm{ppb}$ (acetate and formate) and $1.0 \mathrm{ppb}$ (propionate). $\mathrm{ppb}=\gamma \mathrm{l}^{-1} ; \mathrm{ppt}^{-} \mathrm{ngl} \mathrm{I}^{-1}$. 
Table 2. Statistical parameters for acetate, propionate and formate in all the firn core, 4-14.3 $\mathrm{m}$ section (background level) and 14.3-22 $\mathrm{m}$ section (biomass-burning events)

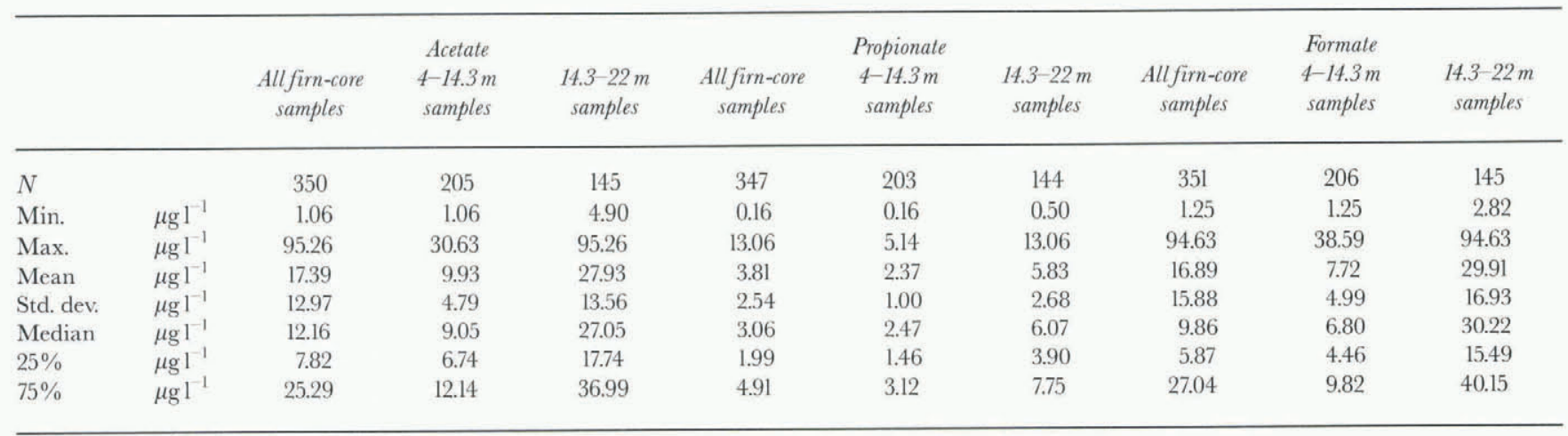

bility values (better than $2.0 \%$ at $50 \mu \mathrm{g} \mathrm{l}^{-1}$ ) and the detection limits (lower than $0.150 \mu \mathrm{g} \mathrm{l}^{-1}$ ) permit the effective determination of these components at very low concentration levels in Antarctic snow. The low detection limits are due to the very stable baseline value, to high peak reproducibility and to low blank values. Figure $2 \mathrm{~b}$ shows the ion chromatogram obtained for a real sample containing fluoride, acetate, propionate, formate and MSA at $\mu \mathrm{gl}^{-1}$ or sub- $\mu \mathrm{gl}^{-1}$ concentration levels, with respect to a blank (polyethylene container) plotted on the same scale. Legrand and others (1993) advised against the use of plastics, to avoid possible contamination. In our experience, accurately cleaned plastic containers (either polyethylene or polypropylene containers, disposable and cheaper than glass bottles) showed low blank values: below the detection limits for propionate and in the range $0.1-1.0 \mu \mathrm{g} \mathrm{l}^{-1}$ for acetate and formate.

\section{Firn-core data discussion}

Among the components analyzed in the firn core, in this paper we pay attention to acetate, formate and propionate.

A reliable dating is necessary to obtain the temporal setting of the samples. The firn-core dating was performed by a combination of seasonal and absolute markers. For seasonal snow-layer identification (relative dating), we used a visual comparison between $\delta^{18} \mathrm{O}$ depth profile $(1-22 \mathrm{~m})$ and a chemical profile (4-22 $\mathrm{m}$ ) obtained by a linear combination of the normalised concentration/depth profiles of three summer markers (MSA, nssSO ${ }_{4}{ }^{2-}$ and $\mathrm{H}_{2} \mathrm{O}_{2}$ ) (Udisti, 1996; personal communication from B. Stenni, 1997). Absolute dating levels were determined by the tritium concentration/ depth profile. This dating has been discussed by Stenni (personal communication, 1997). The dating results showed 64 summer peaks along the firn core $(1-22 \mathrm{~m}$ below the snow surface) corresponding to 63 years from 1990 to 1928 . Chemical data have been measured on a 4-22 m section (1982-28).

Table 2 shows the basic statistical data concerning the distribution of the three carboxylic acids in the firn core. The statistical values can be considered reliable because the three components have been determined on all 351 subsamples (only four values for propionate and one value for acetate are missing). These compounds are present in the Antarctic snow at very low concentrations. The mean values of $16.9 \pm 15.9,17.4 \pm 1333$ and $3.8 \pm 2.5 \mu \mathrm{g} \mathrm{l}^{-1}$, found respectively for formate, acetate and propionate, are very close to those reported by Legrand and others (1993) for Greenland precipitations (only formate and acetate; mean values re- spectively 12 and $13 \mu \mathrm{g} \mathrm{l}^{-1}$ ). Legrand and de Angelis (1995 and 1996) reported mean background Holocene values of $9.3 \pm 1.4$ and $10.7 \pm 1.7 \mu \mathrm{gl}^{-1}$ for acetate and formate at Summit, Greenland.

Figure 3 shows acetate, formate and propionate distribution graphs (box plots). Each box contains $50 \%$ of the data, with the median value displayed as a line. The sample dispersions are quite high, as shown by the relatively large interval between the 25 th and 75 th percentile values (box
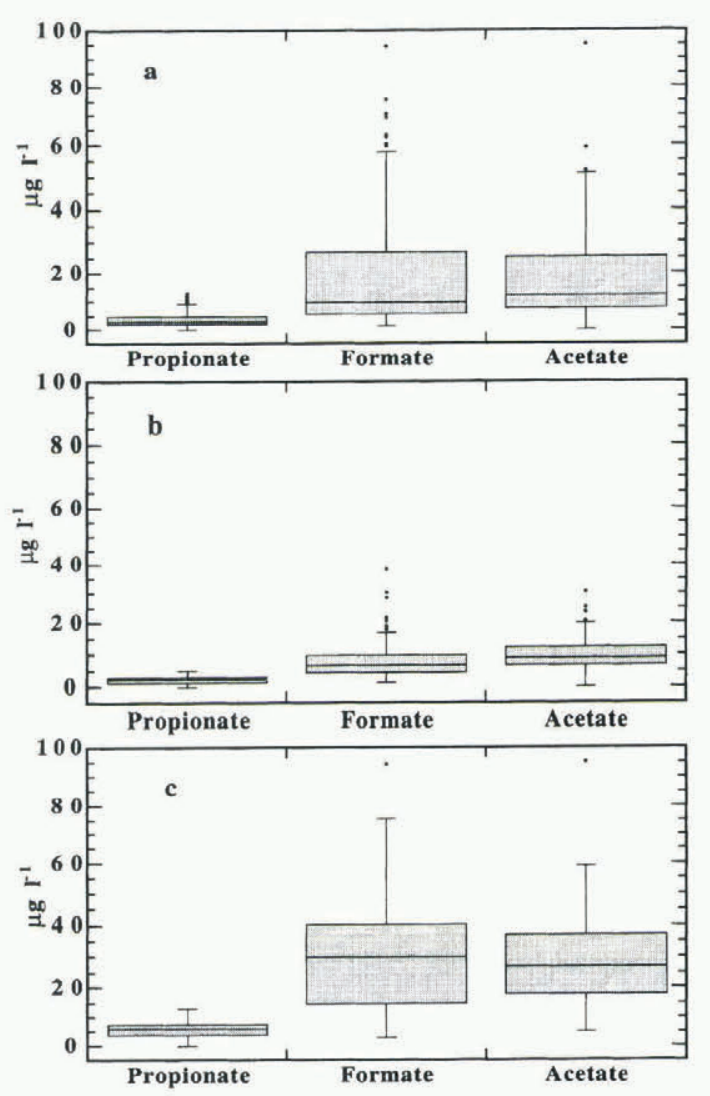

Fig. 3. Box plots of propionate, formate and acetate for all samples ( $a$ ), 4.0-14.3 $\mathrm{m}$ samples ( $b$ ) and 14.3-22 $\mathrm{m}$ sample (c). Each box contains $50 \%$ of the data, with the median value displayed as a line. The top and bottom of the box mark the limits of $\pm 25 \%$ of the variable population (25th and 75 th percentile). The lines extending from the top and bottom of each box mark the minimum and maximum values that fall within an acceptable range (1.5 times the box width). Any value outside of this range (outlier) is displayed as an individual point. 

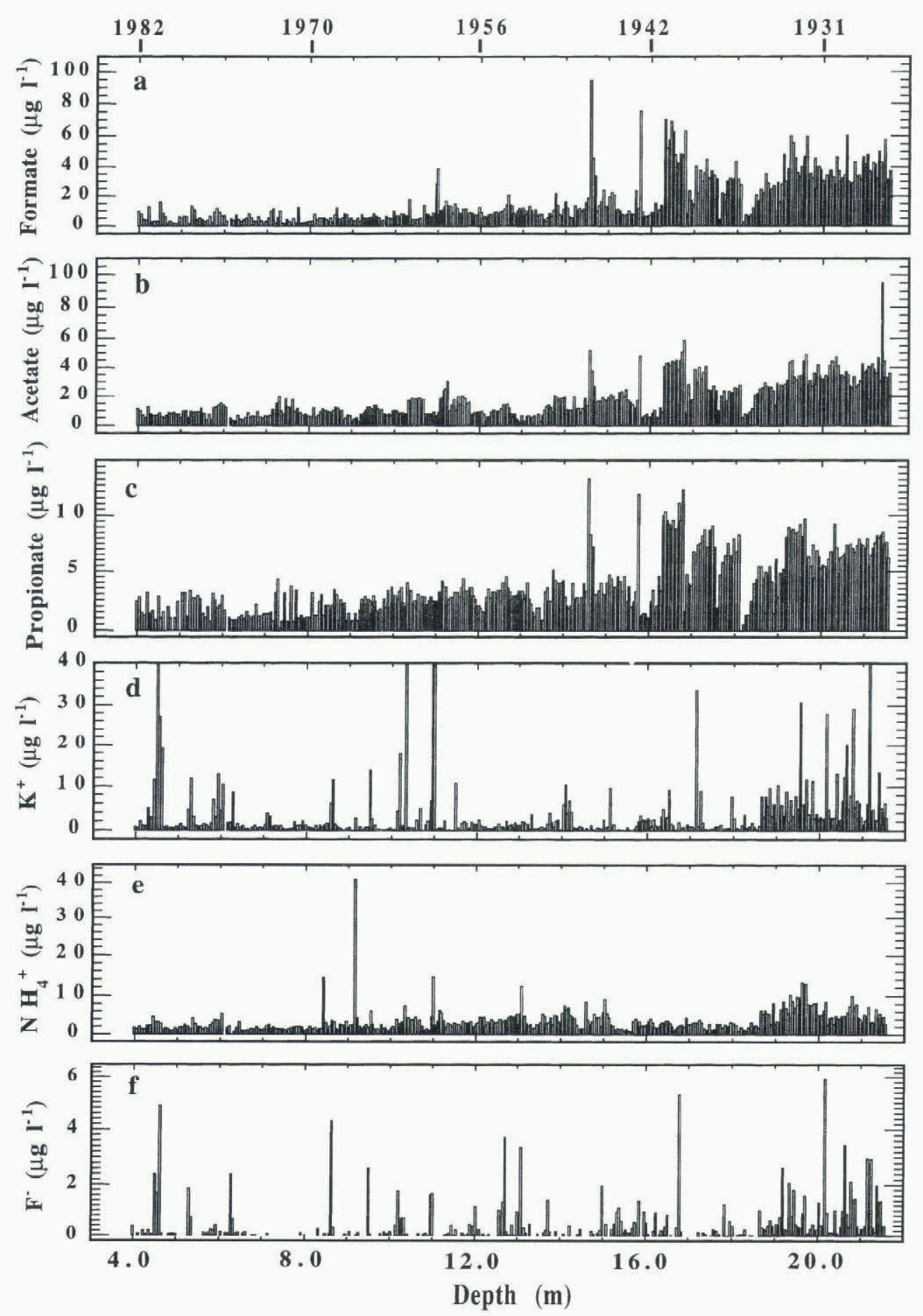

Fig. 4. Concentration/depth profiles of formate ( $a$ ), acetate ( $b$ ), propionate ( $c)$, potassium $(d)$, ammonium $(e)$ and fluoride $(f)$ at Hercules Névéstation.

height) and by the standard deviation value, of the same order of magnitude as the mean value. Moreover, these data dispersions are not symmetrically distributed, as shown by the median values (line in the box) shifted towards the bottom of the box (above all, for formate and acetate) and lower than the mean values. Formate and acetate median values are $58 \%$ and $70 \%$, respectively, of the mean values. A few samples, in fact, have concentration values higher than the mean (up to 5.5 times for formate and acetate and 3.5 for propionate). Such high values are not regularly distributed on all the firn core. Figure $4 \mathrm{a}-\mathrm{c}$ show the concentration/depth profiles for the three components. In the first $15 \mathrm{~m}$ the concentrations for all three compounds are lower than for the total firn-core mean value $(4-14.3 \mathrm{~m}$ depth mean values of $9.9 \pm 4.8,7.7 \pm 5.0$ and $2.4 \pm 1.0 \mu \mathrm{g} \mathrm{l}{ }^{-1}$ for acetate, formate and propionate, respectively). This part of the firn core shows no particular concentration/depth trend, and only a slight concentration increase with depth can be observed for all the components. At 14.6 and $15.7 \mathrm{~m}$ depth (about 1947 and 1943, respectively; personal communication from B. Stenni, 1997), two sharp spikes with relatively high concentrations (up to nearly $100 \mu \mathrm{gl}^{-1}$ ) are found for acetate and formate. Lower maximum values (about $10 \mu \mathrm{g} \mathrm{I}^{-1}$ ), but 3.5 times higher than the mean, are found at the same depths for propionate. For depths lower than $16.0 \mathrm{~m}$, the concentration profiles show a common sharp increase, with values consistently higher than the background. The 14.3-22 m depth (corresponding to the 1948- 

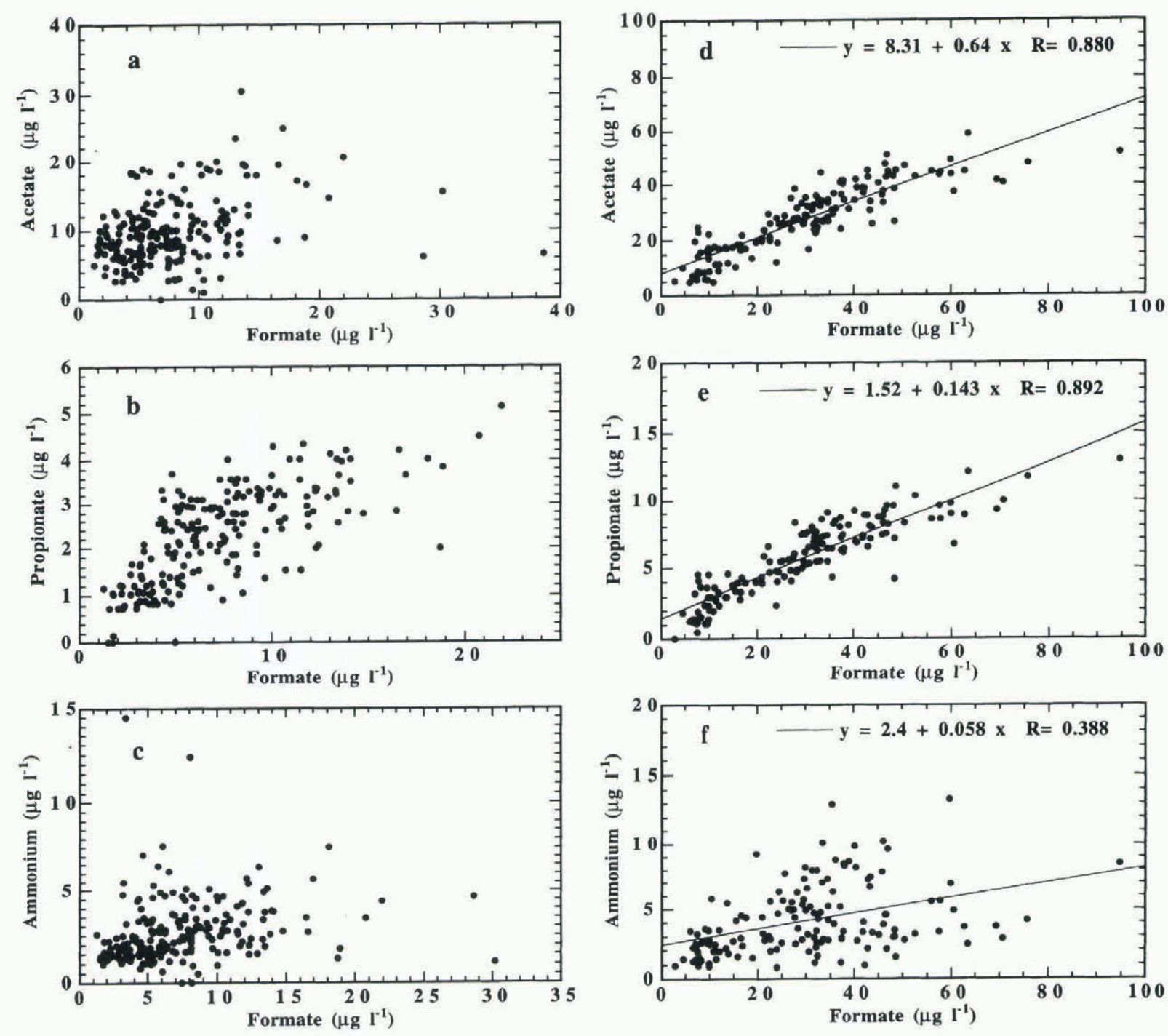

Fig. 5. Correlations of acetate, propionate and ammonium vs formate concentration for $4.0-14.3 m(a-c)$ and $14.3-22 m(d-f)$ samples.

28 period) mean values of $27.9 \pm 13.6,29.9 \pm 16.9$ and $5.8 \pm 2.7 \mu \mathrm{gl}^{-1}$, found for acetate, formate and propionate, respectively, are 2.8, 3.9 and 2.4 times higher than the corresponding $4-14.3 \mathrm{~m}$ depth mean values. This behaviour is shown also by the box plots in Figure $3 \mathrm{~b}-\mathrm{c}$, where an increase of median values and of data dispersion for the deepest firn-core section is clearly evident. Biomass-burning inputs are a possible explanation. In particular, a long-term event seems to be indicated in the 1930 s by the steadily high concentrations from 18 to $22 \mathrm{~m}$ (1936-28).

Figure 5 shows the relationships of acetate, propionate and $\mathrm{NH}_{4}{ }^{+}$with formate (considered as the best biomassburning marker; Legrand and de Angelis, 1995, 1996) in the 4-14.3 m (Fig. 5a-c) and 14.3-22 m (Fig. 5d-f) firn-core section. We can observe that a linear correlation is missing in the upper firn-core part, but it is clearly evident for the organic acids in the bottom (correlation coefficient $R=0.88$, 0.89 and 0.39 for acetate/formate, propionate/formate and ammonium/formate, respectively). The correlation between ammonium and formate is lower than that found by Legrand and de Angelis (1995, 1996) for biomass-burning events at Summit, Greenland. The linear regression slopes indicate a mean ratio of 0.64 and 0.14 for acetate/formate and propionate/formate, respectively.

An acetate/formate ratio of around 10 was found by Talbot and others (1988) from atmospheric measurements rg/10.3189/S026030550001778X Published online by Cambridge University Press 396 during biomass-burning events. During the transport, formic acid production occurs in the plume, so that the acetate/formate ratio reaches values lower than 1 (Legrand and de Angelis, 1995). The acetate/formate ratio found in the firn core $(0.64 \mathrm{w} / \mathrm{w})$ agrees with this result.

High concentration values for carboxylic acids, $\mathrm{NH}_{4}{ }^{+}$, $\mathrm{K}^{+}$and $\mathrm{F}$ are reported as indicating biomass-burning events (Cachier, 1995; Legrand and de Angelis 1995, 1996; Legrand and others, 1995). In order to confirm analogous behaviour, the concentrations of $\mathrm{K}^{+}, \mathrm{NH}_{4}{ }^{+}$and $\mathrm{F}^{-}$in the firn core were plotted vs depth. Figure $4 \mathrm{~d}-\mathrm{f}$ show the relative concentration/depth profiles: a concentration increase is evident starting from $14.3 \mathrm{~m}$ depth for these compounds. This increase is in-phase with carboxylic acid, although a correlation with formate, acetate and propionate spikes at 14.6 and $15.7 \mathrm{~m}$ depth is not visible for $\mathrm{K}^{+}, \mathrm{NH}_{4}{ }^{+}$and $\mathrm{F}$.

The mean concentrations in the bottom of the firn core are $4.2 \pm 6.4,4.3 \pm 2.9$ and $0.67 \pm 0.95 \mu \mathrm{gl}^{-1}$ for $\mathrm{K}^{+}, \mathrm{NH}_{4}{ }^{+}$ and $\mathrm{F}^{-}, 1.3,1.4$ and 2.6 times higher, respectively, than the relative mean values in the $4-14.3 \mathrm{~m}$ firn-core part. For $\mathrm{K}^{+}$, the concentration increase is more evident considering the median value (the $\mathrm{K}^{+}$background mean is affected by some samples with high sea-spray content). An increase of 2.5 times is measured in the firn-core bottom section with respect to the background. This means that a larger number of samples with higher concentration occurs. Similarly, the 
concentration/depth profiles of $\mathrm{Na}^{+}$(sea-spray marker), $\mathrm{nssSO}_{4}{ }^{2-}$ (biogenic and volcanic indicator) and $\mathrm{Ca}^{2+}$ (crustal input) were observed, excluding any alternative explanation of the experimental data. Mean and median values of these compounds did not show any increase trend in the $14.3-22 \mathrm{~m}$ firn-core section with respect to background. Therefore, a biomass-burning event seems to be the more probable explanation for carboxylic acid, $\mathrm{K}^{+}, \mathrm{NH}_{4}{ }^{+}$and $\mathrm{F}$ contemporaneous increases.

High dust levels found in the same firn core at 14.3-22 m depth (Maggi and Petit, 1998) could reinforce the hypothesis of the biomass-burning effects. Preliminary data show that this particulate has a predominant organic composition (about $50 \%$; personal communication from V. Maggi, 1997) and could be constituted by ash or other carbonic material. A structural analysis of the particulate will be performed to confirm the presence of ash. The presence of light particles (such as ash) could explain the very long residence times of the above-mentioned chemical markers and dust in the atmosphere.

\section{CONCLUSIONS}

The eluent-step IC method used for the determination of acetate, formate and propionate in Antarctic snow samples gives a sensitivity sufficient to obtain the first data concerning the distribution of carboxylic acid in northern Victoria Land. The isocratic separation step permits high peak resolution with better baseline stability and lower detection limits with respect to gradient methods.

The application of this method to a $22 \mathrm{~m}$ firn core drilled at Hercules Névé gave background levels of about 10 and $8 \mu \mathrm{g} \mathrm{l}^{-1}$ for acetate and formate (with a ratio close to 1.0) and of about $2 \mu \mathrm{gl}^{-1}$ for propionate in the first $14.3 \mathrm{~m}$ firn-core depth. Preliminary data on relatively high inphase concentration values for carboxylic acids, fluoride, ammonium, potassium and dust evidenced a long-term biomass-burning event. Further analyses on the particulate are needed to confirm the latter source, because of its persistence in atmospheric aerosol for a relatively long period. On the other hand, biomass-burning events in Antarctica can only come from long-range transport. Therefore, their fingerprints should be different with respect to the observations of Legrand and de Angelis $(1995,1996)$ and Legrand and others (1995) at Summit, Greenland, where high, sharp concentration spikes were found. The long-range transport smoothing effects could give slight concentration increases for long time periods.

\section{ACKNOWLEDGEMENTS}

This research was carried out within the framework of a project on glaciology and palaeoclimatology of the Programma Nazionale di Ricerche in Antartide, and financially supported by Ente Nazionale Energia e Ambiente through an agreement with Universita' degli Studi di Milano.

\section{REFERENGES}

Andreae, M. O., R. W. Talbot, H. Berresheim and K. M. Beecher. 1990. Precipitation chemistry in central Amazonia. J. Geophys. Res., 95(D10),
$16,987-16,999$.

Berresheim, H. 1987. Biogenic sulfur emissions from the subantarctic and Antarctic oceans. J. Geophys. Res., 92(D11), 13,245-13,262.

Cachier, H. 1995. Combustion carbonaceous aerosols in the atmosphere: implications for ice core studies. In Delmas, R. J., ed. Ice core studies of global biogeochemical cycles. Berlin, etc., Springer-Verlag, 313-346.

Cheam, V. 1989. Determination of organic and inorganic acids in precipitation samples. f. Chromatog., 482 (2), 381-392.

Cheam, V. 1992. Comparison of ion chromatographic methods for the determination of organic and inorganic acids in precipitation samples. Analyst, 117, 1137-1144.

Dignon, J. 1995. Impact of biomass burning on the atmosphere. In Delmas, R. J., ed. Ice core studies of global biogeochemical cycles. Berlin, etc., SpringerVerlag, 299-311. (NATO ASI Series I: Global Environmental Change 30.)

Jacob, D. J. 1986. Chemistry of $\mathrm{OH}$ in remote clouds and its role in the production of formic acid and peroxymonosulfate. J. Geophys. Res., 91 (D9), 9807-9826.

Jacob, D. J. and S. C. Wofsy. 1988. Photochemistry of biogenic emission over the Amazon forest. 7. Geophys. Res., 93(D2), 1477-1486.

Jacob, D. J. and S. C. Wofsy. 1990. Budgets of reactive nitrogen, hydrocarbons and ozone over the Amazon forest during the wet season. 7. Geophys. Res., 95 (D10), 16,737-16,754.

Keene, W. C. and J. N. Galloway. 1988. The biogeochemical cycling of formic and acetic acids through the troposphere: an overview of current understanding. Tellus, 40B (5), 322-334.

Lambert, G., B. Ardouin and A. Mesbach-Bendezu. 1983. Atmosphere to snow transfer in Antarctica. In Pruppacher, H. R., R.G. Semonin and W. G. N. Slinn, eds. Precipitation scavenging, dry deposition, and resuspension. New York, Elsevier Science Publishers, 1289-1300.

Legrand, M. and M. de Angelis. 1995. Origins and variations of light carboxylic acids in polar precipitation. f. Geophys. Res., 100 (D1), 1445-1462.

Legrand, M. and M. de Angelis. 1996. Light carboxylic acids in Greenland ice: a record of past forest fires and vegetation emissions from the boreal zone. J. Geophys. Res., 101 (D2), 4129-4145.

Legrand, M. and C. Saigne. 1988. Formate, acetate and methanesulfonate measurements in Antarctic ice: some geochemical implications. Atmos. Environ., 22(5), 1011-1017.

Legrand, M., M. de Angelis and F. Maupetit. 1993. Field investigation of major and minor ions along Summit (central Greenland) ice cores by ion chromatography. 7. Chromatog., 640 (1-2), 251-258.

Legrand, M., M. de Angelis, H. Cachier and A. Gaudichet. 1995. Boreal biomass burning over the last 80 years recorded in a Summit-Greenland ice core. In Delmas, R. J., ed. Ice core studies of global biogeochemical cycles. Berlin, etc., Springer-Verlag, 347-360. (NATO ASI Series I: Global Environmental Change 30. .

Maggi, V. andJ.-R. Petit. 1998. Atmospheric dust concentration record from the Hercules Névé firn core (northern Victoria Land, Antarctica). Ann. Glaciol., 27 (see paper in this volume).

Murray, F. 1989. Acid rain and acid gases in Australia. Arch. Environ. Contam.Toxic., 18, 131-136.

Pourchet, M., J. F. Pinglot and C. Lorius. 1983. Some meteorological applications of radioactive fallout measurements in Antarctic snows. 7 . Geophys. Res., 88(C10), 6013-6020.

Rocklin, R. D., C. A. Pohl and J. A. Schibler. 1987. Gradient elution in ion chromatography. J. Chromatog., $411(1), 107-119$.

Talbot, R. W., K. M. Beecher, R. C. Harriss and W. R. Cofer, III. 1988. Atmospheric geochemistry of formic and acetic acids at a mid-latitude temperate site. J. Geophys. Res., 93(D2), 1638-1652.

Talbot, R.W., M. O. Andreae, H. Berresheim, D. J. Jacob and K. M. Beecher. 1990. Sources and sinks of formic, acetic and pyruvic acids over central Amazonia. 2. Wet season. J. Geophys. Res., 95 (D10), 16,799-16,811.

Tsitouridou, R. and H. Puxbaum. 1987. Application of a portable ion chromatograph for field site measurements of the ionic composition of fog water and atmospheric aerosols. Int. 7. Environ. Anal. Chem., 31, 11-22.

Udisti, R. 1996. Multiparametric approach for chemical dating of snow layers from Antarctica. Int. 7. Environ. Anal. Chem., 63, 225-244.

Udisti, R., E. Barbolani and G. Piccardi. 1991. Determination of some organic and inorganic substances present at ppb level in Antarctic snow and ice by ion chromatography. Ann. Chim., 81 (7-8), 325-341.

Udisti, R., S. Bellandi and G. Piccardi. 1994. Analysis of snow from Antarctica: a critical approach to ion-chromatographic methods. Fresenius' 7 . Anal. Chem., 349 (4), 289-293.

Watts, S. F., P. Brimblecombe and A. J. Watson. 1990. Methanesulphonic acid, dimethyl sulphoxide and dimethyl sulphone in aerosols. Atmos. Environ., $\mathbf{2 4 A}(2), 353-359$. 